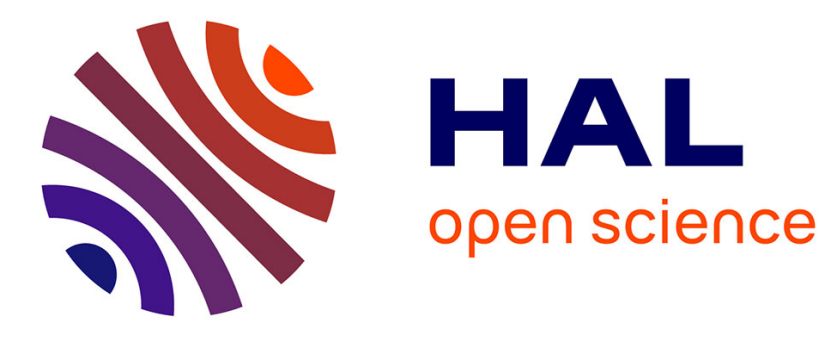

\title{
Bottlenose dolphin (Tursiops truncatus) sonar slacks off before touching a non-alimentary target
}

Yann Doh, Fabienne Delfour, Elodie Augier, Hervé Glotin, Christian Graff, Olivier Adam

\section{- To cite this version:}

Yann Doh, Fabienne Delfour, Elodie Augier, Hervé Glotin, Christian Graff, et al.. Bottlenose dolphin (Tursiops truncatus) sonar slacks off before touching a non-alimentary target. Behavioural Processes, 2018, 157, pp.337-345. 10.1016/j.beproc.2018.07.015 . hal-01879562

\section{HAL Id: hal-01879562 \\ https://hal.science/hal-01879562}

Submitted on 6 Nov 2020

HAL is a multi-disciplinary open access archive for the deposit and dissemination of scientific research documents, whether they are published or not. The documents may come from teaching and research institutions in France or abroad, or from public or private research centers.
L'archive ouverte pluridisciplinaire HAL, est destinée au dépôt et à la diffusion de documents scientifiques de niveau recherche, publiés ou non, émanant des établissements d'enseignement et de recherche français ou étrangers, des laboratoires publics ou privés. 


\section{Bottlenose dolphin (Tursiops truncatus) sonar slacks off before touching a non-alimentary target}

Similar content as published in Behavioural Processes journal

\section{Yann Doh}

Association GUALIBA, Routhiers, Rue Dumesnil, 97130 Capesterre Belle Eau, Guadeloupe, France

Corresponding Author, 0033 671397912; yanndoh.m2@gmail.com

\section{Fabienne Delfour}

Parc Astérix, Plailly, France

and Laboratoire d'Ethologie Expérimentale et Comparée (LEEC), Equipe d'accueil 4443, Université Paris 13, Sorbonne Paris Cité, Villetaneuse, France

\section{Elodie Augier}

Centre de biologie du comportement, Univ. Grenoble Alpes, CNRS, LPNC, 38000 Grenoble, France

\section{Hervé Glotin}

Université de Toulon, Aix Marseille Univ, CNRS, LIS, DYNI, Marseille, France and Institut Universitaire de France, France

\section{Christian Graff}

Laboratoire de Psychologie et de Neuro Cognition (LPNC), Univ. Grenoble Alpes, Univ. Savoie Mont Blanc, CNRS, LPNC, 38000 Grenoble, France

\section{Olivier Adam}

Sorbonne Université, Centre National de la Recherche Scientifique, UMR 7190, Institut Jean Le Rond d'Alembert, F-75005 Paris, France

and Institute of Neurosciences Paris Saclay, CNRS UMR 9197, Université Paris Sud, Orsay France

To cite as: 
Doh, Y., Delfour, F., Augier, E., Glotin, H., Graff, C. and Adam, O., 2018. Bottlenose dolphin (Tursiops truncatus) sonar slacks off before touching a non-alimentary target. Behavioural processes, 157, pp.337-345

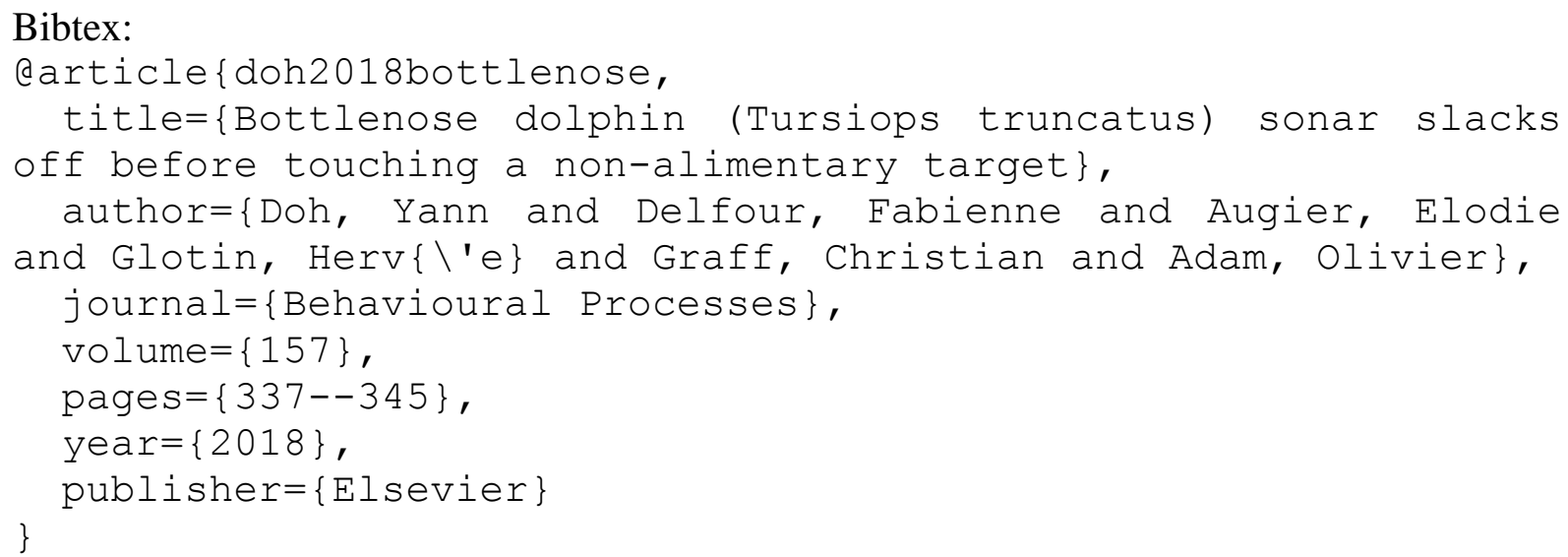

\begin{abstract}
$\underline{\text { Abstract }}$
Odontocetes modulate the rhythm of their echolocation clicks to draw information about their environment. When they approach preys to capture, they speed up their emissions to increase the sampling rate of "distant touch" and improve information update. This global acceleration turns into a "terminal buzz" also described in bats, which is a click train with drastic increase in rate, just as reaching the prey. This study documents and analyses under human care bottlenose dolphins' echolocation activity, when approaching non-alimentary targets. Four dolphins' locomotor and clicking behaviours were recorded during training sessions, when sent to immersed objects pointed by their trainers. Results illustrate that these dolphins profusely use echolocation towards immersed non-alimentary objects. They accelerate click emission when approaching the target, thus displaying a classical terminal buzz. However, their terminal buzz slackens off within a quarter of second before the end of click train. Typically, they decelerate to stop clicking just before they touch the object using their rostrum lower tip. They do not emit clicks as the contact lasts. In conclusion, when exploring inert objects, bottlenose dolphins under human accelerate clicking like other odontocetes or bats approaching preys. Bottlenose dolphins' particular slackening-off profile at the end of the buzz shows that they anticipate the moment of direct contact, and they stop just as real touch relays distant touch of the object.
\end{abstract}

\title{
$\underline{\text { Key-words }}$
}

Bottlenose dolphin, echolocation, approach phase, terminal buzz, inter-pulse interval, slackening-off. 


\section{Introduction}

Toothed whales such as dolphins, porpoises and sperm whales are equipped with bio-sonar analogous to that of bats (Griffin, 1944), allowing navigation and detection (Thomas et al., 2003). They echolocate with broadband pulses called clicks (Herman and Tavolga, 1980; Au et al., 2000), that are repeatedly emitted in trains. Clicks are short transitory signals: 50 to $80 \mu \mathrm{s}$ for bottlenose dolphins (Tursiops truncatus) (Mann et al., 1998). The duration between two adjacent clicks or inter click interval (ICI) is variable within a train as well as between two trains and ranges from $0.8 \mathrm{~ms}$ to $5 \mathrm{~ms}$ for a buzz (Luis et al., 2016). Click emission is not automatic but controlled (Moore and Pawloski, 1990). The animal modulates amplitude, frequency content and rhythm of the clicks depending on the echolocating function (e.g., navigation, target detection or discrimination, prey pursuit, social contact).

Modulation of echolocation rhythm during foraging and prey capture has been first described in bats hunting mosquito using ultrasonic pulses comparable to clicks into three phases: search, approach, and terminal, associated to characteristic acoustic behaviours (Griffin, 1958; Griffin et al., 1960). Search phase consists in a navigation by the predator in the environment to detect and localize potential preys. It involves ICIs from about 50 to $100 \mathrm{~ms}$. The second phase coined prey approach begins when a prey is detected, approximately at 2-4 m (Kalko, 1995): the animal moves toward the target and pursues it if necessary. It is associated with an acceleration in emission rate, with ICIs about 50 to $10 \mathrm{~ms}$. Finally, the terminal phase, when the predator is close enough to attempt a catch, is associated with a "terminal buzz", comprised of ICIs about 4 to $7 \mathrm{~ms}$. The "buzz" corresponds to the sound heard from an ultrasonic converter, when successive pulses are no more perceived as distinct clicks but when the accelerated train forms a continuous humming.

This phenomenon is found by convergent evolution in other echolocating species, such as sperm whales Physeter macrocephalus (Miller et al., 2004), beaked whales Ziphidae (Madsen et al., 2005) and short finned pilot whales (Globicephala macrorhynchus) (Aguilar et al. 2008) and beluga whales (Delphinapterus leucas) (Ridgway et al., 2014) recorded from sound and position sensors directly fixed on the animals. During the search phase, they emit spaced and regular clicks (Mullins et al., 1988; Whitehead and Weilgart, 1991). Trains turn to buzzes or "creaks" during capture events attempts that are inferred from accelerations and rapid body movements recorded on the animal (Mohl, 2003; Zimmer et al., 2005, Laplanche et al., 2006). In captivity, few studies on echolocation during prey capture have been documented in odontocetes (Verfuss et al., 2009; Miller, 2010; Wisniewska et al., 2014; Ridgway et al., 2015). Synchronized underwater video - and highfrequency sound - recording showed a speed-up in the animals' clicks when they approach the prey and a decrease when it is at less than $1 \mathrm{~m}$. When dolphins succeed in capturing a prey, they could emit a "victory squeal" 0.2 to $20 \mathrm{~s}$ after capture (Ridgway et al., 2015; Dibble et al. 2016).

As more pulses are emitted for a same duration, the terminal buzz represents a higher sampling rate in time, correlated through movement with a finer resolution in space. The subsequent faster update of information (Britton and Jones, 1999) responds to the need of stronger temporal and spatial resolution in order to reach a small moving target (Madsen et al., 2005; Verfuss et al., 2009). Similarly, needs in electro-location explain why night-active weakly-electric fish increase their rate of discharge pulses when swimming and 
when facing a novel object (Bauer 1974, Avril \& Graff 2007).

The present study investigates the echolocation course in bottlenose dolphin (Tursiops truncatus), during the presentation of static non-alimentary objects. It is based on an ICI duration analysis inspired from electric fish work (Graff, 1989). Unlike most investigations in captive dolphins (e.g. Harley et al. 2003), this experiment attempts to explore the echolocation behaviour displayed without performance constraint. Dolphins were not blindfolded and no perceptive task was imposed on the animals. Their use of echolocation was spontaneous, yet they were led to objects. For a better knowledge of the context of their emission, acoustic signals were recorded simultaneously with underwater locomotor behaviour. To control for contextual variables, subjects were individually called and driven by their trainers to the presence of single inert objects. This limited the circumstances of recording and focused on standardized conditions of free interaction. The animals were thus reinforced coming close - not for touching - the objects, and not for echolocating because the trainers were deaf to the clicks.

The experiment documents echolocation in captive T. truncatus, when vision is available in their familiar pools and in normal daily context. Second, as good quality click trains were abundantly recorded, their rhythm was investigated to show their reaction to the pointing to objects immersed near them, with relation to their behaviour. Third, as dolphins eventually touched an object with their rostrum when coming closer, characteristic increases in emission rate with terminal buzz were quantified, comparable to that already described in the approach and terminal phase of prey capture in bats and other odontocetes.

\section{Method}

\subsection{Subjects and housing}

Observations focused on four bottlenose dolphins ( $\mathrm{T}$. truncatus) housed at Parc Astérix dolphinarium (France) at daytime, during seven regular training sessions, in February 2012. Animals were two females (Beauty and Baily) and two males (Guama and Balasi), respectively $40,13,30$, and 8 years old. The two older dolphins were born in the wild while the two younger ones were born in Parc Astérix. Animals move and interact at will with six other conspecifics in three interconnected pools, two indoors and one outdoors. About the behavior of captive dolphins, regular published ethograms show their diversity and closeness to the ones of wild conspecifics.

Using a known hand gesture, the trainers commanded the four tested dolphins to swim alone to the recording area. The experiment took place in the largest pool $(60 \mathrm{~m} * 28 \mathrm{~m}$, maximal depth $4.5 \mathrm{~m}$ ) situated outdoors, comprising two advanced platforms facilitating contact with trainers and an underwater window gallery facilitating video recording.

\subsection{Experimental context}

The experiment consisted in simultaneously recording acoustical signals and behaviour of individual dolphins with relation to underwater presentation of initially unfamiliar objects. Objects were harmless and non-eatable: a holed white PVC disc, a holed white wooden disc, a red plastic fin and a plastic bottle with red colored content (Fig. 1). These objects did not emit any kind of acoustical or electrical signals. 
A

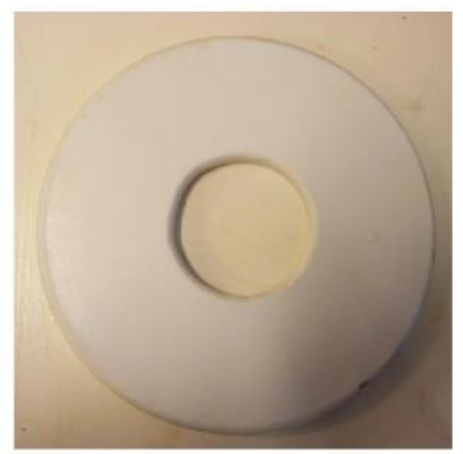

C

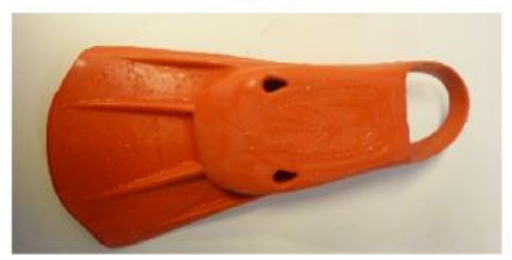

B

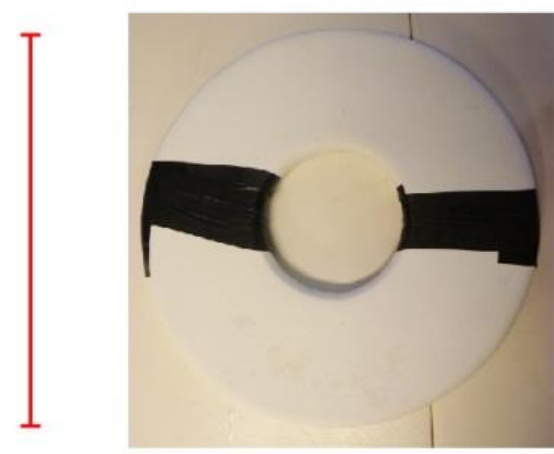

D

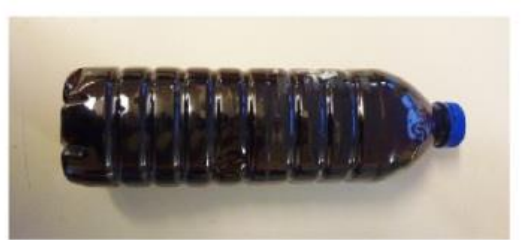

Fig. 1. Presented objects. The central vertical bar scales $30 \mathrm{~cm}$. A, object \#1: PVC disk, $2 \mathrm{~cm}$-thick, 650 g. B, object \#2: wooden disk; $2.5 \mathrm{~cm}$-thick, $600 \mathrm{~g}$. C, object \#3: flexible plastic fin, $350 \mathrm{~g}$. D, object \#4: colored-water plastic bottle, $500 \mathrm{~g}$.

Since dolphins showed interest for electronic objects (Goodson et al., 1988), the silent omni-directional hydrophone was attached to the object to form an objecthydrophone device. Moreover, clicks are produced ahead in a directive beam in-axis of the animal (Au et al., 2010): the objecthydrophone association prevented from signal attenuation occurring when acquisition takes place out of this beam (Nowacek, 1999).

The experiment was conducted during daily training sessions. Sessions took place five times a day and lasted for $20 \mathrm{~min}$. The ten dolphins were called in front of the outdoor beach (Fig. 2), working with their trainer. Since dolphins understand target-pointing (Pack and Herman, 2004, 2007), trainers sent individually off each the four participant dolphins by a hand gesture at the opposite side of the pool (as in Verfuss et al., 2009) close to the objects. Seclusion prevented as much as possible to record a mix of sounds emitted by different dolphins, without having to physically isolate the individual from its social group. When the focus dolphin arrived close to the experimental platform, a reward (whistle, food and/or vocal encouragement) was given by a second trainer. The experimenter then immersed one object-hydrophone device vertically along the pool wall, about $30 \mathrm{~cm}$ below the surface, for approximately 20 to $30 \mathrm{~s}$ of presentation in front of the window facing the camera. From above the surface, the trainer pointed the index finger to the object under water.

Dolphins were repeatedly submitted to object \#1 and to an alternative object. Each session, object \#1 was presented first, and more often $(\mathrm{M}+/-\mathrm{SD}=$ $6.6+/-1.4$ times) than the second one $(3.6+/-1.0$ times $)$. For three subjects, the alternative object, either object \#2 or \#3, was changed between the two sessions. Balasi participated in one session only, using alternative object \#4 because of previous encounter with the two other ones. It often happened that several dolphins responded and arrived together to the presenting spot. Their unexpected spontaneous individual and social behaviours precluded better control of encounters, as would have been required to 
test for specific effects of objects or object change.

Dolphins were free to station, to explore the device or to swim away. We avoided all constraint to the animals. When the trial ended, the device was removed, the animal was sent away and another dolphin could come for a new trial. This procedure was repeated as often as possible, to obtain a maximum of trials for each dolphin and each presented object. In the end, two trials for the same individual in the same session were separated by about $5 \mathrm{~min}$.

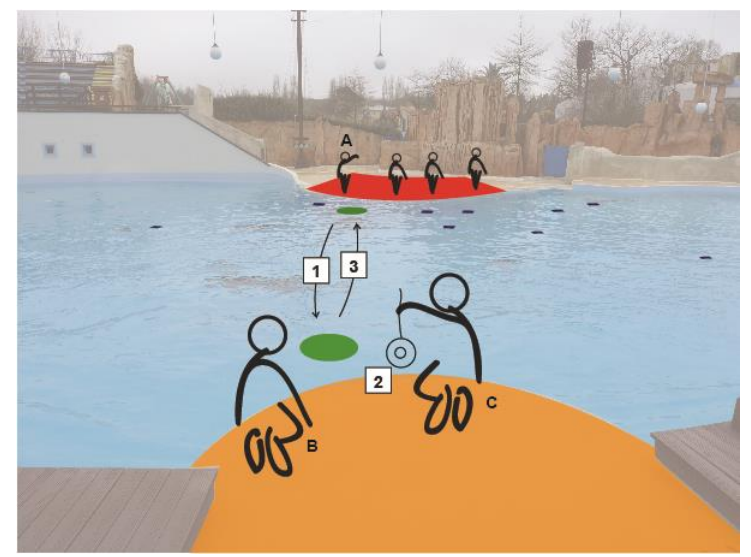

Figure 2. Experimental set up: (1) Trainer A on the remote platform sends one dolphin by a hand gesture to the opposite side of the pool, where it is received by trainer $B$ on the experimental platform. (2) Experimenter C immerses the object-hydrophone device for about $30 \mathrm{~s}$ while B points to it. (3) The dolphin is sent back to the remote platform. Green ellipses symbolize the focus dolphin and blue squares the others.

\subsection{Recordings}

Each training session was filmed through the underwater viewing gallery, under the experiment platform, by a fixed camera (Panasonic Lumix DMC-FZ38, frame rate: $33 \mathrm{fps}$ ) to obtain an accurate behavioral observation while the dolphin emitted sounds and interacted with the object. A hydrophone (Cetacean Research C54XRS) attached to the objects and connected to an analog-to-digital converter (Tascam HD-P2) with an integrated adjustable preamplifier allowed sound signal acquisition. Preliminary tests allowed to adjust the gain to $5 \mathrm{~dB}$ and keep it set for the whole experiment. The converter saved the sampled signal in *.WAV format on a SD card at $44.1 \mathrm{kHz}$ sampling rate and coded on 16 bits. These recording parameters ensured the task of acoustic events detection for ICI estimates. The expected values are mostly higher than $1 \mathrm{~ms}$ (Luis et al., 2016). However, 44.1 $\mathrm{kHz}$ sampling is a limiting factor for clicks spectral analysis, as bottlenose dolphin's peak frequency is over the resulting Nyquist frequency. Some clicks were also audible on the camera soundtrack, facilitating audio-video matching of locomotor and acoustic behaviour. Total duration of cumulated sequences of video and audio recording reached about 100 minutes over two days.

\subsection{Behavioral observations}

We distinguished two main behavioral contexts around echolocation: "exploration" defined as a distant scan of the object, not ending with any physical contact and "approach" that occurred when the dolphin moved toward the object-hydrophone device and touched it, in a brief or lasting contact (Atem et al., 2009; Verfuss et al., 2009).

As the trainer pointed to the device, dolphins eventually positioned against it with their rostrum. We called this behaviour "positioning". During a long static positioning on the device a dolphin could briefly loose the contact because of the object moving with wavelets. The animals approached again, we called these low amplitude movements repositioning considered as minor adjustments.

\subsection{Behavioral analysis}

A total of 74 approaches were satisfactorily filmed with an exploitable soundtrack. Qualitative sound description of recorded approaches revealed if the dolphin clicked while approaching, if it stopped clicking at contact onset, and if it restarted clicking while the contact lasted. 
For a further extensive quantitative analysis of ICIs (as in Verfuss et al., 2009), thirty-eight of them were conservatively excluded, as soon as signal-to-noise ratio was too low or several dolphins clicked simultaneously at the object.

A consistent amount of approaches was selected and 36 good-quality trains (48 $\%$ of the complete dataset) were further analyzed into details. The observed acoustic behaviour is thus present at least for $1 / 2$ approaches which is thus confidently representative of a repetitive acoustic behavior within this dolphin group. When possible, the accurate instant of contact with the device was noted; this was the case in all trials where the dolphin touched a part of the hydrophone (cable or tip) because physical contact is then audible on the recording. When the very moment of contact was impossible to determine, because it was not audible in the sound file, we used the video record to propose a range where it had to be contained. Such ranges remained inaccurate when the rostrum contact was hidden behind the object and because of the limited time precision of the slow-motion capacities of our video hardware (33 fps).

\subsection{ICI processing}

The raw signals in WAV format were preprocessed using the free audio software Audacity (v1.2.3, SourceForge.net). By using high-pass filtering and adjusting the gain, temporal adjustment of the sequences of interest was made and further prepared the click amplitude level above the background noise The ICI time course of the sequence was then extracted with computer assistance.

Using a custom-built detection program written in Matlab, clicks were detected by a trigger based on amplitude (absolute values), then selected and characterized with additional comparison parameters according to biologicallyrelevant criteria.
The detection of standing out amplitude events was operated using first a 34 ms sliding window. In such delay, the amplitude was not likely to be affected by changes in distance and orientation of the source to the hydrophone. Second, the algorithm selected clusters of neighboring samples exceeding the mean by 2.5 to 4.5 times the standard deviation, as peaks in putative clicks. The position of the peak was estimated by selecting the sample with the highest amplitude. High-amplitude detected samples points were matched with next ones located closer than 15 places apart, i.e. within $0.34 \mathrm{~ms}$ from one another, which is approximately the duration of our recorded and filtered clicks. Third, as cetaceans never abruptly change their signal amplitude within a train, it provides a consistency criterion of the click amplitude. Then, the peaks were assimilated to clicks only if their amplitude was in a range of $30 \%$ of the weighted mean amplitude of the three preceding clicks $(5 / 11$ for the last click, $3 / 11$ for the first and second clicks). Fourth, after an assessed click, no other click was expected during a refractory phase; the corresponding delay (1.25 to $1.7 \mathrm{~ms}$ ), was chosen based on observed ICIs, to be long enough to prevent repeated detection of the same click, and short enough to prevent ignoring the next one.

After detecting the clicks, the program yielded the list of ICIs in milliseconds. Defects as ambient noise, omissions (a click is present but is not detected) and false alarms (program detects a click whereas there is none) were both characterized and corrected when possible or the sequence was discarded. Sequences were finally converted as chronograms, to visualize the evolution of ICI (Y-axis) in passing time (X-axis) for each click train. Despite the filtering process, some visible defects as sudden variations of the ICI for isolated points remained present in a few sequences used for analysis. These artifacts could come from the animal sound production or a 
false detection. Nevertheless, they were tolerated as having no incidence on the global trend of the curves. The moment of contact with the device was additionally plotted onto the graph.

Chronograms with a logarithmic Yscale provided a clear visual image of the temporal course of clicking on raw ICI data, as it emphasizes relative differences on large scales (e.g. between approach and terminal phase ICIs) as well as on small scales (within the buzz). Terminal buzzes were present. However, an unexpected profile of ICI lengthening became visible towards the end of the buzzes. Data were therefore standardized using the stop of the train, close to the moment of contact, as zero of the time axis (abscissa), a procedure similar to pre-triggering technique on an oscilloscope. ICI train profiles were then compared qualitatively on chronograms and quantitatively using parametric and non-parametric statistics. A better comparison of data issued from 36 selected sequences was prepared by standardizing on a countdown in ICI serial order.

A global image was obtained by breaking down trains into segments. For each individual train, ICIs were pooled together by successive steps of 32 , beginning at the last ICI in the train and going backwards to the total number of ICIs of the sequence. The number of 32 ICIs was arbitrarily chosen as exceeding the sample size where most statistics may be interpolated (Sokal \& Rohlf, 1973). After the breakdown, a median duration was computed over the 32 ICIs of each train segment. The overall image of the 36 approach sequences was portrayed by computing, for the eight last successive steps, the minimum, first quartile, median, third quartile, and maximum of the segment's median ICI. Note that the number of segment medians (sample size) used for this image decreases from the very last, to the second -, third -, ...- , eighth last one preceding the stop, because the number of segments varies for each click train according to the total number $\mathrm{N}$ of ICIs in the corresponding sequence. Thus, some sequences had only one complete segment $(32<\mathrm{N}<64$, the last one alone, present in all 36 sequences), whole the longest sequences had virtually many more segments one. However, medians were not computed from the initial ICI of the longest sequence, i.e. for all sequences segments. A maximum of eight segments ( $\mathrm{N}>256$, present in 18 sequences) were taken into consideration; beyond this maximum, data were no more present for most trains, because they were too short. Medians and other nonparametric rank statistics were privileged in order to discard other artifacts and outliers' effect.

When a phenomenon was observed abundantly in a given situation, its occurrence was tested with a binomial test to be present against a 50\%-50\% distribution, to attest that it occurs in most cases (more than half). When it was to be generally observed in a situation, the binomial test was conducted against a 75\%-25\% distribution to attest that it occurred in a vast majority of cases.

\section{$\underline{3 \text { Results }}$}

Dolphins spontaneously and profusely used echolocation towards immersed objects pointed by a familiar trainer. Above $100 \mathrm{~min}$ of recording provided an extensive number of echolocation sequences, with hundreds of click trains, also observed during preliminary tests.

\subsection{Behavioral observations}

When sent over by their trainer and after the device was immersed, the dolphins clicked and sometime glanced at their trainer from under the surface or with the head out of the water. They displayed static positioning for a brief moment or for up to ten seconds. The contact with the device occurred at the first or second presentation, generally after an observation 
phase staying afar. During a long static positioning on the device, dolphins sometimes repositioned themselves. The physical contact always concerned a limited area of the lower part of rostrum,
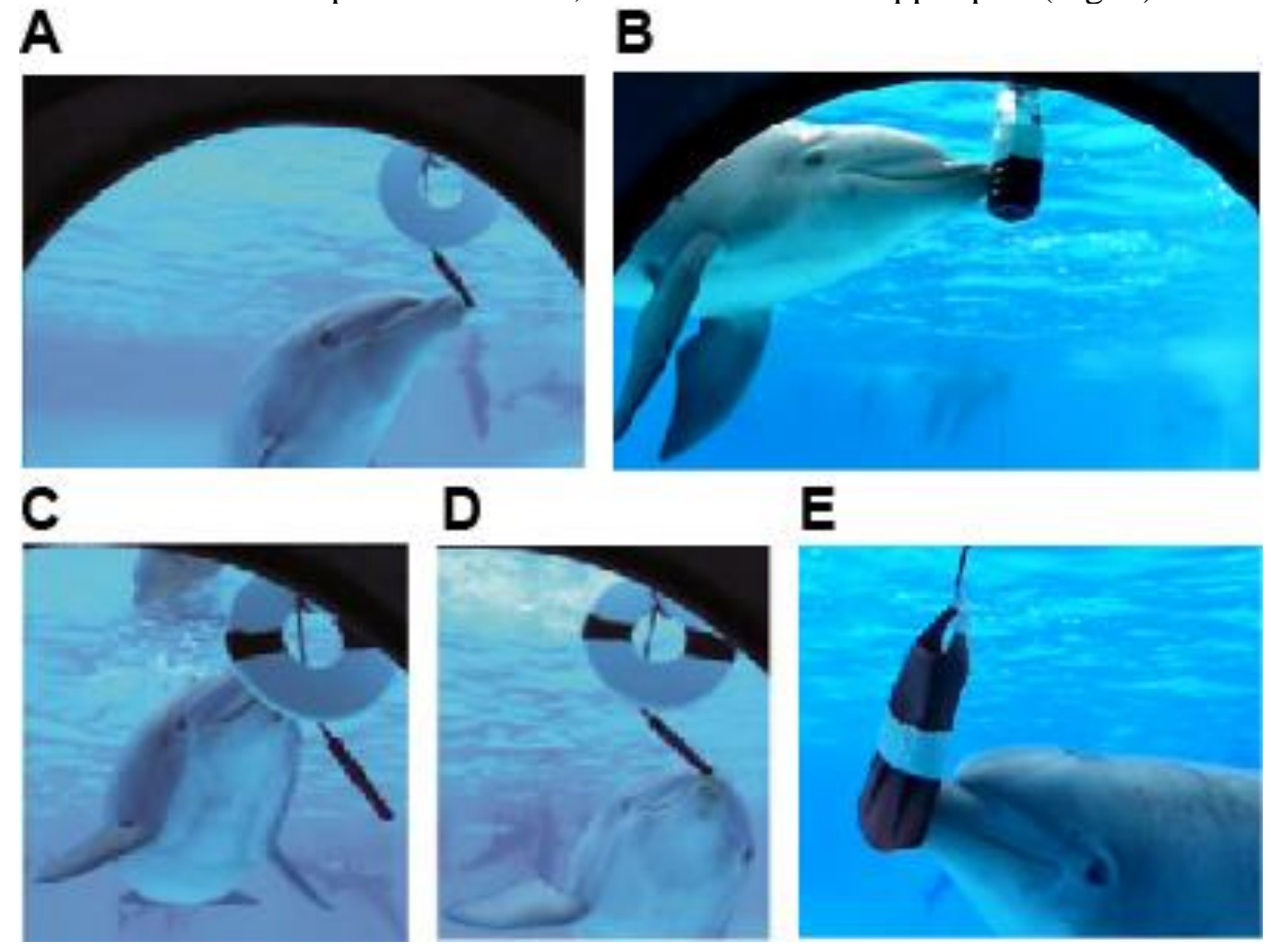
its rostrum upper part (Fig. 3).
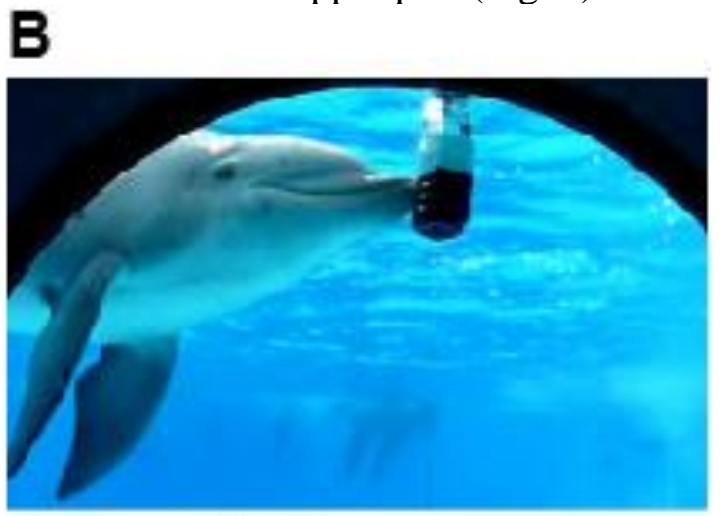

Fig 3. Examples of positioning on the object/hydrophone device. Panel $A, D$ and $E$ are for Guama, panels $B$ and $C$ for Balasi and Beauty respectively. Contacts involve the lower rostrum, except for panel D where Guama lifted the hydrophone.

\subsection{Echolocation during approach}

Use of echolocation during approach. The 74 approach sequences identified on video were subdivided into 56 normal approaches (i.e. no repositioning) and 17 repositioning. Out of 56 normal approaches, 50 (89.29\%) were accompanied by a click train. Conversely, clicks were present in 2 out of 17 repositioning. Their presence significantly depended on the type of approach $\left(\chi^{2}\right.$ test $(1, \mathrm{~N}=73)=38.25, \mathrm{p}<0.05)$, suggesting that echolocation was no longer used for minor adjustment once the target was reached.

Acceleration in approach phase. For each of the 36 sequences workable for ICI rhythm analysis, a chronogram was plotted that represents the ICI duration no contact with any other body part was observed during the whole experiment. Except for Guama, who sometimes lifted the hydrophone for a few centimeters with

\section{然}

uama,

with respect to its date in passing time (Fig. 4) set with the train stop as zero. A linear trendline was adjusted to each chronogram, to determine the evolution of emission rhythm. Out of 36 trendlines, 31 showed a negative slope, which corresponded to a global acceleration in emission when the animal gets close to the target in $86.11 \%$ of the cases, i.e., a significant majority (binomial test (.5, $\mathrm{N}=36) p<0.05$ ). All linear trend lines did not fit well to the data (mean $R^{2}=.36$; $\mathrm{SD}=.27$ ) because during approach the click train generally included two or more accelerations, and some decelerations. The negative trendline was attributed to a stronger speed-up while getting closer to the end of the click train (see examples on Fig. 4), as observed on 34 individual chronograms on 36 . These $94.4 \%$ of the cases are a significant large majority 
(binomial test $(0.75, \mathrm{~N}=36) \mathrm{p}<0.05)$. Thus, dolphins usually accelerated their click emission while approaching object devices, and the shorter ICIs occurred close to the end of the train. However, this acceleration was not linear, and the trend was tempered by frequent decelerations before the extreme, final speed-up, but also (as will be shown later) by some slackening-off before the train ends.
A

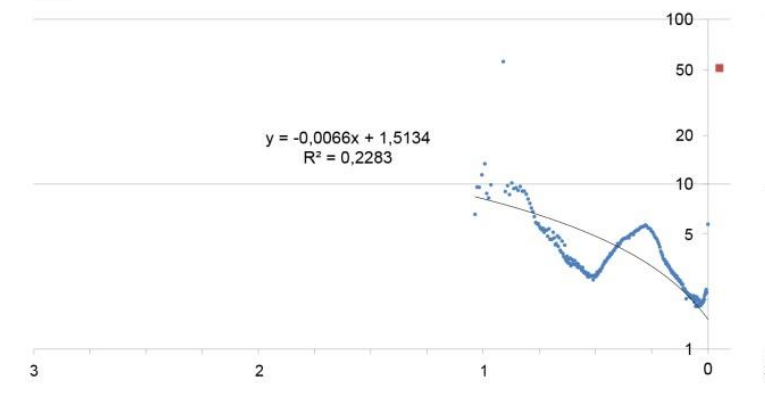

C

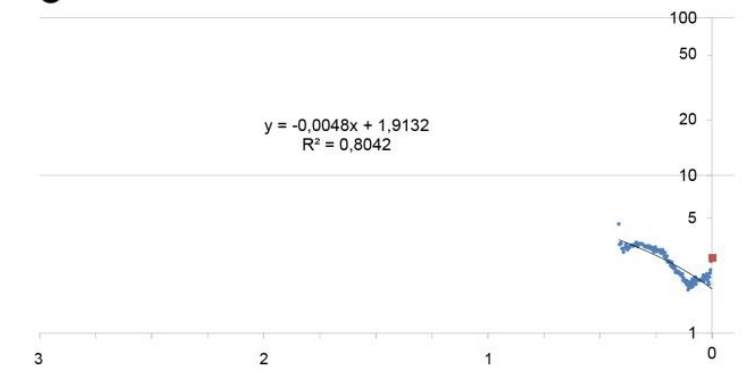

B

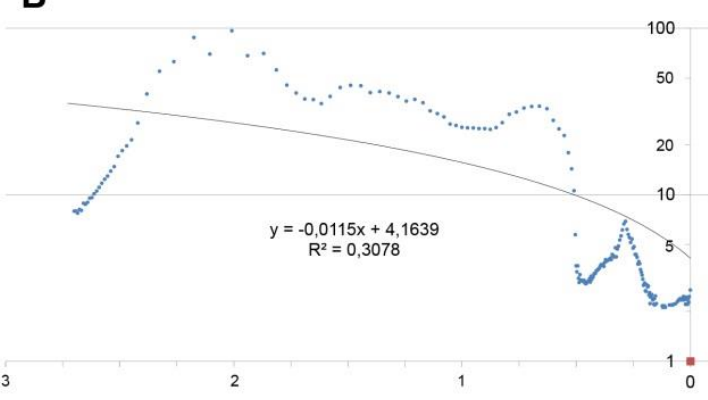

D

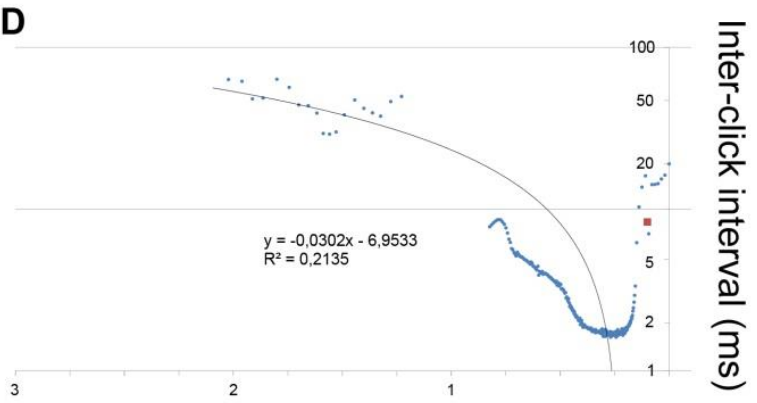

E

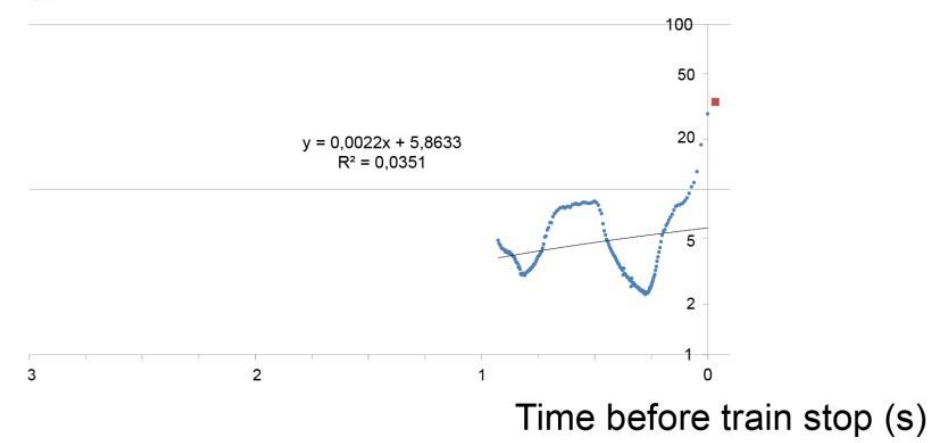

Fig. 4. Examples of chronogram for each individual dolphin: $\mathrm{ICl}$ duration in milliseconds (log scale) as a function of countdown time from train stop in milliseconds. Linear trend lines show global acceleration for Panel A (Guama), B (Baily), C (Beauty), and D (Balasi), but not for Panel E (Balasi) because of the final deceleration. Note that linear trend lines appear as curved because of the logarithmic Y-scale. Red square is the contact onset with the object; its height shows the delay with the preceding click (Y-axis).

Terminal buzz slackens off. Despite much inter-and intra-individual variability, compacted data from a breakdown in 32ICI segments also demonstrated the acceleration (ICI decrease) on a global image that focuses on the termination of the approach (Figure 5). The rhythm got more than twice faster, i.e. median ICI reduced to less than half, from the $8^{\text {th }}$ last to the very last - segment. However, shortest ICIs were not emitted during but before the last segment. 


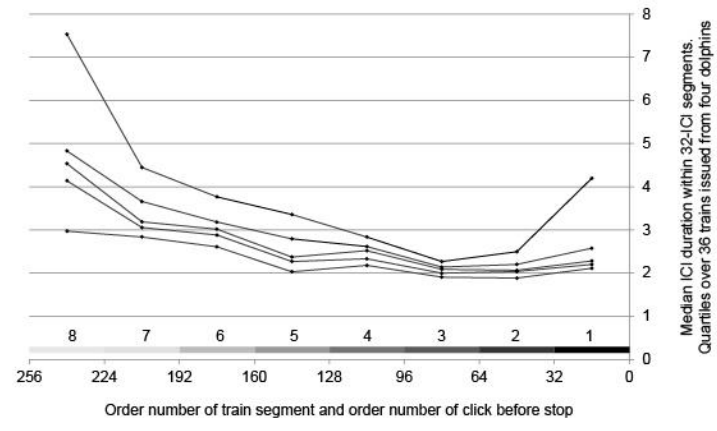

Fig. 5. General profile of bottlenose dolphins' clicking behaviour when arriving close to the objects. From top to bottom: maximum, third quartile, median, first quartile and minimum among $\mathrm{N}=36$ sequences, of the median ICI duration of portions grouping 32 sample ICls. The order number of segments - and of cutpoint ICls - is counted down with respect to the stop of the trains.

Dolphins decelerated their emissions (increased ICIs) just before ending their click trains. The portion of shortest median ICI, about $2 \mathrm{~ms}$, was typically the $3^{\text {rd }}$ or $2^{\text {nd }}$ one before the stop (32nd to 96th last ICI). This pattern seemed characteristic to our dolphins' terminal buzz. This was not an artifact due to data pooling (Fig. 6). In 32 out of 36 cases, in the last quarter of a second before the stop, chronograms fell to a minimum, after what trains ended with an increase in ICIs. This pattern of the end of the click train was actually visible on $89.89 \%$ of the cases, a significantly large majority (binomial test, $(0.75, \mathrm{~N}=36) \mathrm{p}<0.05)$. The minimum ICI value was therefore not observed at the last clik train, it generally occurred 0.25 to 0.05 second before the stop (Q3, median, Q1 = 240, 130, $54 \mathrm{~ms}$ respectively). When swimming closer to an object, the dolphin typically accelerated its click train; however it decelerated and stopped at the last moment of reaching the target.

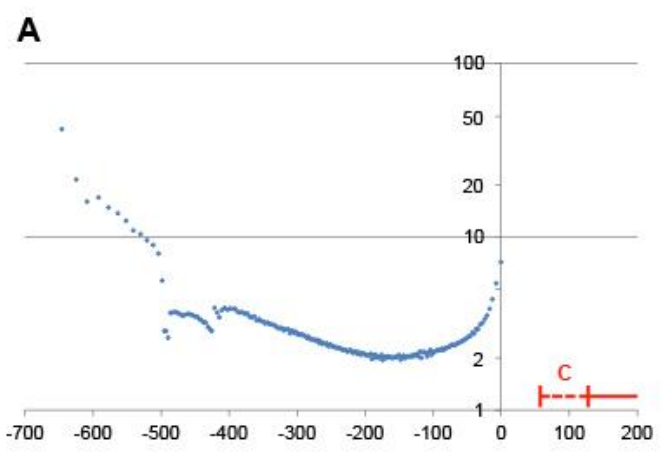

B

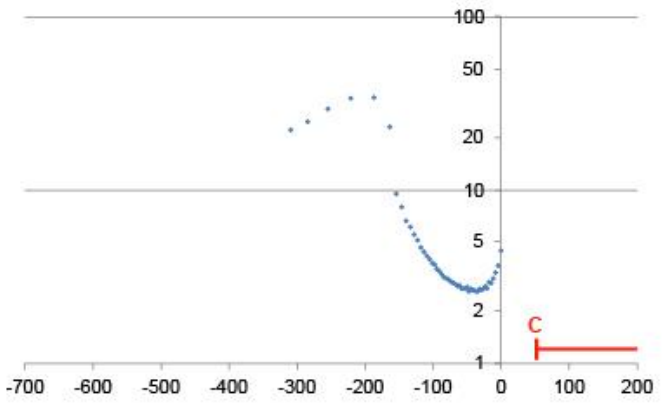

C

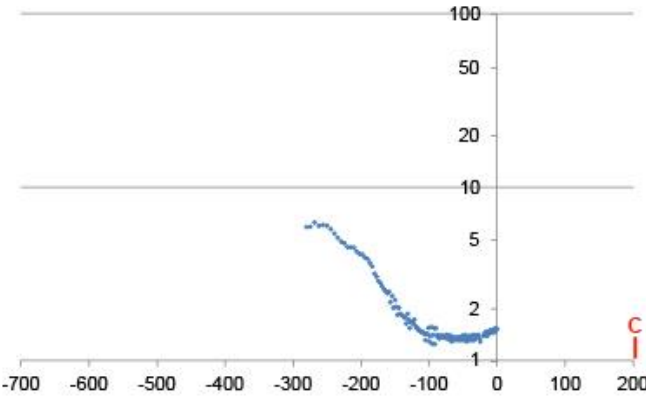

Time before train ends $(\mathrm{ms})$

Fig. 6. Examples of terminal buzz pattern with respect to contact onset, for Guama ( $A$ and $B$ ) and Balasi (C). X-axis, countdown time from train stop, in milliseconds; Y-axis, ICl duration, in milliseconds (log scale). Red bars mark the beginning of contact with the object/hydrophone device, with red $\mathrm{c}$ indicating contact onset, either precisely (Panel B and C) or within a range including it (panel $A$ ).

\subsection{Touch takes over from echolocation}

Click-train ends before contact. This deceleration and the following stop were not triggered by the contact, as they occurred before it. Out of 52 times when dolphins had clicked in approach phase, 39 stopped their click train before the contact instant, and only 6 afterwards; the contact- 
to-stop interval remained unknown for the remaining 7. Therefore, for the 45 sure cases, $87 \%$ had stopped their click before contact, which is a significantly large majority (binomial test $(.5, \mathrm{~N}=45) p<.05)$. For those cases, the click train stopped for maximum $1030 \mathrm{~ms}$ before the contact $(\mathrm{N}=$ 39; $\mathrm{M}=233 \mathrm{~ms} ; \mathrm{SD}=331.6$ ). If they did not stop before touching, the click train only continued for no more than $185 \mathrm{~ms}$ after the contact $(\mathrm{N}=6 ; \mathrm{M}=87 \mathrm{~ms} ; \mathrm{SD}=$ 67.4). Overall, trains generally terminated a tenth to a hundredth of a second before the contact (Q1-, median-, Q3-delay = 9, 46, $137 \mathrm{~ms}$ respectively).

To sum up, dolphins usually stopped clicking just before touching the target with their rostrum. The interval between the last click and the contact was always (except for 1 sequence out of 39) greater than the last ICI before. It is not the occurrence of contact at one moment after a click in a train that makes it instantly stop. Dolphins anticipated the moment of contact.
No click while contact lasts. The stop observed on the 52 trains click trains of approach was usually definitive whether it occurred before, or exceptionally, shortly, after contact onset; for six of them only did the dolphins resume clicking before the end of positioning; in 42 cases the dolphins remained silent during the whole time contact was maintained; the 4 other cases are undetermined. Dolphins did not use echolocation simultaneously with the touch modality (binomial test $(0.75$, $\mathrm{N}=48) p<0.05$ ).

\subsection{General pattern illustrated on one example}

To summarize, the animal accelerated more its echolocation emission than it decelerated while approaching a non-alimentary inert object (Figure 7). As the dolphin got closer to the target, it accelerated to a maximum (minimum ICI), then slackened off and definitely stopped just before contact. The animal did not resume clicking while the contact lasted.

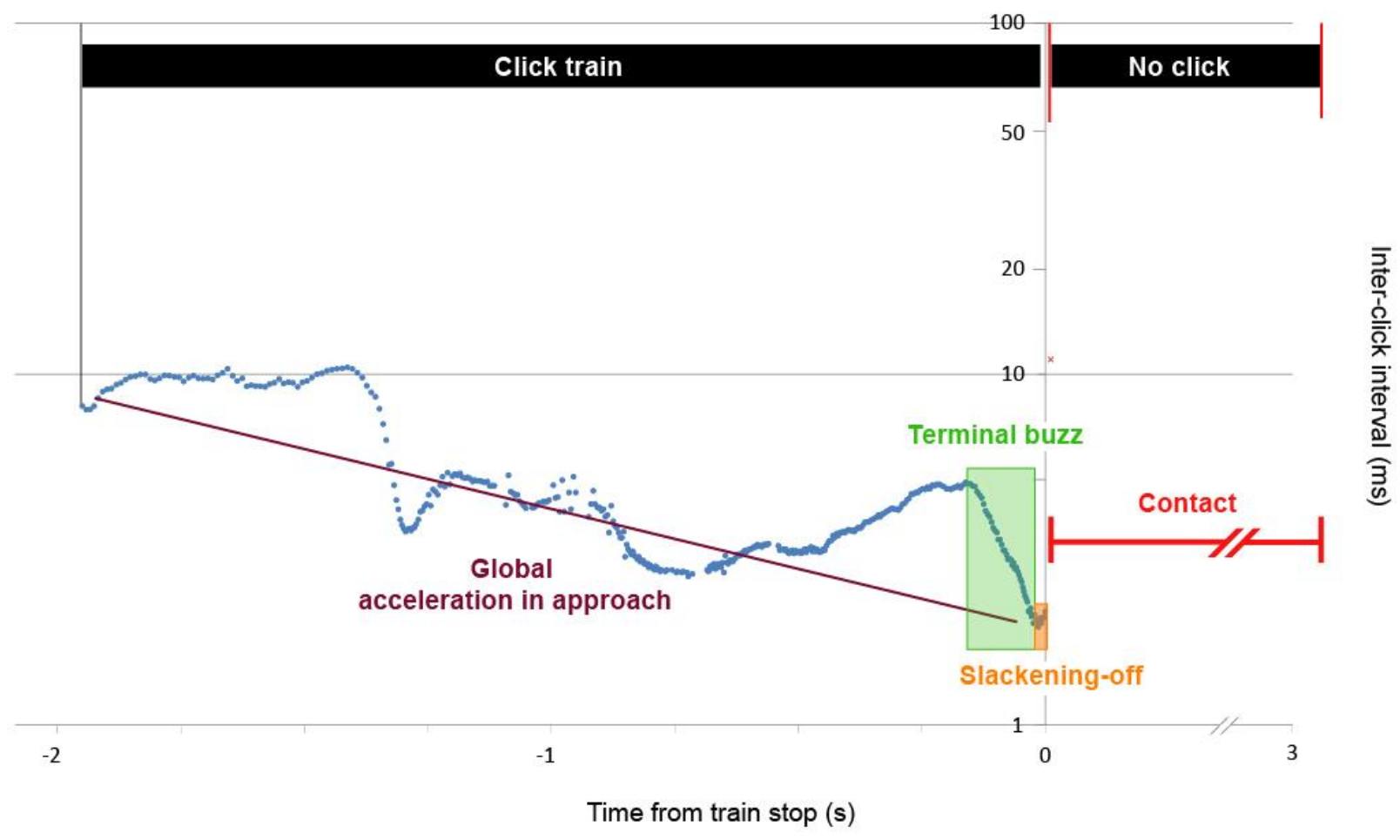

Fig. 7. Example of click train showing the major temporal pattern emitted in approach. $x$-axis is countdown time from the end of the click train in milliseconds, and $\mathrm{y}$-axis is the $\mathrm{ICl}$ duration in milliseconds (log scale). 


\section{Discussion}

\subsection{Dolphins emit terminal buzz at target approach}

Terminal buzz pattern of clicking was prevalent when swimming towards an object. The time course of click emission during the approach phase to a target and during the terminal phase before contact is comparable to those described for other taxa (chiropters and other odontocetes) (Griffin et al., 1960; Verfuss et al., 2009; Miller et al., 2004; Madsen et al., 2005). When heading to an inert target, our dolphins displayed acceleration similarly to bats, harbor porpoises and sperm- and beaked whales capturing a prey. However, the preceding searching phase, corresponding to target - or prey - research at longer distance, seemed difficult to investigate under human care conditions. This phase may be considered, with additional means, in future data sampling designs, to complete the classical threephase picture.

Functional explanations for the observed pattern are similar to those applied to other species. Global acceleration in emission increases the sampling rate, therefore the amount of collected data in a portion of time. Data may concern an object position (hence the term "echolocation") but also its shape, movement and even quality (Harley et al., 2003). In the wild, a rapid update of a small prey's trajectory compensates for the lack of maneuverability before attempting a catch (Miller et al., 2004). In non-feeding situation too, the animal needs accuracy to position the rostrum on a reduced area, such as the tip of the hydrophone in our conditions. Maximal precision is required to avoid a violent contact of the skin with a target or with any obstacle, because the rostrum is so sensitive (Mauck \& Dehnhardt, 2000).

In prospective phases, a neurophysiological explanation of echo processing click by click makes sense, because the ICI is much longer than the Two-Way travel Time (TWT) therefore it leaves additional time for higher brain processing. By contrast, in buzz phases, the ICI of a few seconds nears the estimated TWT. This very short interval is no longer related to the distance to the target, and it does not give enough time for more cognitive processing to interpret echoes (Wisniewska et al. 2014). This suggests that such processing is operated on the click train as a whole, and online, i.e., during the train. It allows the dolphin to perceive and process from the acoustic radiation, the target could be mentally highlighted, allowing to obtain details not only on its position even at a very short distance (the dolphin have a visual contact of the target), but other specific information like shape, interior and exterior textures, fine movements, and if the target is alive or an object.

In short, various animals orienting towards an object or tracking a prey by echolocation pulses require speeding up the emission rate thus the terminal buzz fulfills a function of rapid and accurate update. In our four dolphins, locating and moving towards was explicitly induced by the trainers' pointing gestures to man-made targets, a very common interaction with humans for dolphins under human care. This practice most likely emerged because dolphins are prone to understand finger and eye - pointing (Pack and Herman, 2004, 2007). The observation that individuals usually kept clicking when positioning on an object already encountered, but not when repositioning on the same one after a brief loss of contact, suggests that echolocation is not limited to special novel situations, but that echolocation parameters may be stored in short-term memory.

\subsection{Dolphins' terminal buzz slackens off}

Our study discloses a special profile in Tursiop truncatus' terminal buzz, i.e. the very final deceleration at the end of 
the click train, which had not been mentioned before, in the pattern common to many different species. Anatomical studies on dolphin click generator does not suggest any explanation about emission of such ICI variations, especially at the end of the click trains (Cranford et al. 1996, 2003, Madsen et al. 2010, Cranford et al., 2011). Different explanations of this slackening off will be explored further studies:

Energy expenditure - Usually terminal buzzes acceleration is accompanied by a loss in amplitude (Atem et al., 2009). Most likely, a speed/amplitude trade-off compensates for the important cost in energy involved in higher repetition rate. In the terminal buzzes we recorded, dolphins were not only emitting quickly, but they kept emitting strongly. We think that the invested energy is important, and the mechanism of repetition cannot be stopped too abruptly (Ridgway et al., 2012). This final slackening off is thus observed in rate, not in amplitude. However, the slackening off has not been systematically observed for each recorded approach which is weakening this assessment of mechanical constraint.

\section{Correspondence between motion} behaviour and the echolocative clicks rate - Many articles associate toothed whale buzzes with changes in the body acceleration rate (Johnson et al., 2004; Miller et al., 2004; Arranz et al., 2016). For sperm whale, ICI variation and the whale pitch angle are correlated (Zimmer et al., 2003; Laplanche et al., 2005; Fais et al., 2016) and ICI control to target range has been observed on bottlenose dolphin (Au et al 1993). As this sound production is used to "scan" a target or the environment, it is consistent to admit that the animal intentionally or not, modulates the sample rate (ICI) when maneuvering and interacting. The slackening off could be the consequence of a "heavy braking" just before touching the object with the rostrum.
"Victory squeal" - Ridgway et al.
(2014) described these specific clicks before eating. He assumes that these clicks were emitted only in front of an eatable target. The acoustic features of these specific clicks are different than regular click train (Ridgway et al., 2015). However, it was emitted with the strict objective to eat (or to be associated with a eatable target that it is not in our experiment).

To conclude about the dolphins' echolocation slackening off: 1) it could be non-intentional due to the vocal generator itself, for anatomical or mechanical reasons the generator reduces its emission. However, if it was a mechanical relaxation phenomenon, the ICI would decrease not increase as it was the case here; 2) or it could be intentional: the dolphins adapt their ICI to the physical and spatial parameter of the target.

\subsection{Click and touch}

A focus on the instant when contact takes place, right after the end of the buzz, also highlights a cross-modal relationship of touch with echolocation, for perception of the same object. Prior studies have already shed some light on cross-modal integration of sonar with vision (Pack and Herman, 1995). Physical touch surely deserves attention as it is an important part of dolphins' affiliative behaviour, also sought after by humans attracted by them.

Recordings show that contact takes place with the rostrum tip, usually its lower part. This distinct posture may well favor association with sight, as eyes are positioned laterally and oriented ventrally in cetaceans. But above all, the lower jaw is the locus of reception for click echoes (Brill et al. 1988). This reception may be hampered by the object's direct contact thus rendering echolocation useless or not possible. Echolocation, as vision, is useful for extracting information at distance; this "distant touch" may be no more appropriate at point blank range. Either the 
beam originated from the melon does not reach the echoing spot, or powerful sounds reflected from too close may cause aversive reverberation to the nearlytouching rostrum. Click vibrations provoke mechanical effects: powerful clicks can be used to caress conspecifics or even to knock preys (Herzing 1996, 2003). Thus reciprocally, the reverberation onto the object would disturb or jam the reception of tactile stimuli. A stop in clicking that anticipates the contact guarantees the integrity of tactile stimuli and respects the sensitivity for echolocation stimuli.

\subsection{Influence of the trainers' pointing gesture}

The person who pointed to the target was familiar and well-known by the tested dolphins. Dolphins are used to respond to and to follow their trainers' gestures. We also know that dolphins are able of joint attention (Pack and Herman, 2004 ; 2007) so the trainer's hand gesture is informative for the animals that might comprehend it as an informative signal to go to a specific location, to look at or to look for something, to pay attention to something or to increase their vigilance towards something. To avoid this bias, the target should have been immerged in the absence of a familiar person around and then we would have recorded the spontaneous dolphins' behaviors. The presence of a familiar person giving consigns might have had some influences on the behavioral response of the dolphins. However, the trainers did not teach and/or reward the dolphins for producing clicks. Moreover, the objective of our experiment was not to interpret the clicks as dolphins do, but to analyze acoustic features, especially the variations of the ICI and intensities in order to highlight how dolphins choose to emit these click trains. Then possible biases introduced by the trainers' pointing gesture to the tested dolphin should not have impacted our results.

\section{Conclusion}

This study analyzed dolphins' behaviors and acoustical signals production while approaching an immersed non-alimentary target. According to the scientific literature on dolphins' echolocation, the present results showed that during the approach phase echolocation is followed by an acceleration of the click rate. However, unlike what has been previously demonstrated, we show here a consistent amount of cases highlighted a deceleration of the click rate, a terminal buzz slackens off, just before touching the object and no click was emitted during and after the physical contact with the object. Moreover, it seems that by processing both visual and acoustical information the dolphin gains more knowledge on the target and, particularly on the possibility to touch it without any harm, which could finally lead the dolphin to get in physical contact through its rostrum with the target. This sequential senses processing (vision and acoustics then touch) might function as a reassurance for the animal leading him/her to touch the scanned object. This strategy contributes to better understand echolocation. Dolphins produce echolocation clicks in very close proximity to the target, even if they get information from visual observation. Echolocation might not only be a distant tool that could inform about a target the dolphin cannot see, but it seems that information given by echoes reflected by the target are complementary to visual information. Echolocation gives dolphins information on the distance of the target, its size, form, outside and inside texture, density and its displacement. All this information builds a complex multi-modal image of the target. Physical stimulations engender visual, tactile, auditory sensations then after cognitive processing with emotional contents they become perceptions. Thus, one can imagine that a visual and/or acoustic stimulation (the dolphins see the 
target) that has generated certain sensations and perceptions is relayed (or completed) by tactile stimulation that generates a tactile sensation, itself generating a perception of the target. The emotion content is important since it has been showed that dolphin could produce a victory squeal after capturing a prey (Dibble et al., 2016).

Bottlenose dolphins' global accelerations and final buzz when approaching a static non-alimentary target, resemble strategies generally used by echolocating or electro-locating species performing precise actions for navigation or prey capture. In our original results, this distant touch used at close range finally slackens off until it stops shortly before the onset of full contact. Our basic gathering of click records encourages for further investigation on spontaneous echolocation behaviour in captive and wild dolphins. The sequence of pulse intervals can easily be analyzed finely, based on tools classically developed for other biological models of pulse rhythm (Bauer 1974, Avril \& Graff 2007). Clicking activity provides objective measures of bottlenose dolphins' umwelt.

\section{References}

Arranz Alonso, P, DeRuiter, SL, Stimpert, AK, Neves, S, Friedlaender, AS, Goldbogen, JA, Visser, F, Calambokidis, J, Southall, BL \& Tyack, PL, 2016. Discrimination of fast click series produced by tagged Risso's dolphins (Grampus griseus) for echolocation or communication. J. Exp. Biol, 219(18), pp. 2898-2907. DOI: 10.1242/jeb.144295.

Atem, A. C., Rasmussen, M. H., Wahlberg, M., Peterson, H. C., \& Miller, L. A., 2009. Changes in click source levels with distance to targets: studies of free-ranging white-beaked dolphins Lagenorhynchus albirostris and captive harbour porpoise Phocoena phocoena. The International
Journal of Animal Sound and its Recording, 19, 49-65.

Au, W. W.,1993. The Sonar of dolphins. New York: Springer-Verlag New York Inc.

$\mathrm{Au}$, W. W., Houser, D. S., Finneran, J. J., Lee, W., Talmadge, L. A., \& Moore, P. W., 2010. The acoustic field on the forehead of echolocating Atlantic bottlenose dolphins (Tursiops truncatus). J. Acous. Soc. Am., 128(3), 1426-1434.

Au, W. W., Popper, A. N., \& Fay, R. R., 2000. Hearing by whales and dolphins. New York: Springer Handbook of Auditory Research.

Avril, A. \& Graff, C., 2007. Active electrolocation of polarized objects by pulse-discharging electric fish, Gnathonemus petersii. J. Comp Physiol A., 193(12), 1221-1234.

Bauer, R., 1974 Electric organ discharge activity of resting and stimulated Gnathonemus petersii (Mormyridae). Behaviour, 50 (3/4), 306-323.

Berns, G. S., Cook, P. F., Foxley, S., Jbabdi, S., Miller, K. L., \& Marino, L., 2015. Diffusion tensor imaging of dolphin brains reveals direct auditory pathway to temporal lobe. In Proc. R. Soc. B, 282(1811), p. 1203.

Brill, R. L., Sevenich, M. L., Sullivan, T. J., Sustman, J. D. and Witt, R. E., 1988. Behavioral evidence for hearing through the lower jaw by an echolocating dolphin (Tursiops truncatus). Mar. Mam. Sci., 4, 223-230.

Britton, A. R., \& Jones, G., 1999. Echolocation behaviour and prey-capture success in foraging bats: laboratory and field experiments on Myotis Daubentonii. J. Exp Biol, 202, 1793-180. 
Cranford, T. W., and Amundin, M. E., 2003. Biosonar pulse production in odontocetes: the state of our knowledge. in Echolocation in Bats and Dolphins. Ed. J. A. Thomas, C. F. Moss and M. Vater), Chicago: The University of Chicago Press, pp. 27-35.

Cranford, T. W., Amundin, M., and Norris, K. S., 1996. Functional morphology and homology in the odontocete nasal complex: implications for sound generation. J. Morphol., 228, 223-285.

Cranford, T. W., Elsberry, W. R., Van Bonn, W. G., Jeffress, J. A., Chaplin, M. S., Blackwood, D. J., Carder, D. A., Kamolnick, T., Todd, M. A., Ridgway, S. H., 2011. Observation and analysis of sonar signal generation in the bottlenose dolphin (Tursiop truncatus): Evidence for two sonar sources. J. Exp. Mar. Biol. Ecol., 407, 81-96.

Fais, A, M. Johnson, M., Wilson, M, N. Aguilar Soto, N, Madsen P. T., 2016. Sperm whale predator-prey interactions involve chasing and buzzing, but no acoustic stunning. Scientific Reports 6, 28562.

Dibble, D. S., Van Alstyne, K. R., \& Ridgway, S., 2016. Dolphins signal success by producing a victory squeal. Int. J. Comp. Psychol., 29(1).

Goodson, A. D., Klinowska, M., \& Morris, R., 1988. Interpreting the acoustic pulse emissions of a wild bottlenose dolphin (Tursiops truncatus). Aquatic Mammals, 14(1), 7-12.

Graff, C., 1989. Firing activity of the weakly-electric fish Marcusenius macrolepidotus (Mormyridae, Teleostei). Logarithmic distribution of inter-pulse intervals and sequential inequality testing. Behaviour 109, 258-284.
Griffin, D. R., 1944. Echolocation by blind men, bats and radar. Science, 100, 589590.

Griffin, D., 1958. Listening in the dark: the acoustic orientation of bats and men. New Haven: Yale University Press.

Griffin, D. R., Webster, F. A., \& Michael, C. R., 1960. The echolocation of flying insects by bats. Animal Behaviour, 8, 141154.

Halm, M.P., Poquin, D., Lestaevel, P., Chancerelle, Y. \& Graff, C., 2006. Brain and cognitive impairment from burn injury in rats. Burns, 32(5), 570-576.

Harley, H. E., Putman, E. A., \& Roitblat, H. L., 2003. Bottlenose dolphins perceive object features through echolocation. Letters to Nature, 424, 667-669.

Herman, L. M., \& Tavolga, W., 1980. The communications systems of cetaceans. In M. Herman (Ed.), Cetacean behavior: Mechanisms and functions. New York: Wiley-Interscience, pp. 149-209.

Herzing, D. L., 1996. Vocalizations and associated underwater behavior of freeranging Atlantice spotted dolphins, Stenella frontalis and bottlenose dolphins, Tursiops truncatus. Aquatic Mammals, 22(2), 61-79.

Herzing, D. L., 2003. Social and non social uses of echolocation in free-ranging Stenella frontalis and Tursiops truncatus. In J. A. Thomas, C. F. Moss, \& M. Valter (Eds.), Echolocation in Bats and Dolphins, Chicago: The University of Chicago Press, pp. 64-85.

Johnson, M., Madsen, P. T., Zimmer, W. M. X., de Soto, N. A., and Tyack, P. L., 2004. "Beaked whales echolocate on prey," Proc. R. Soc. London, Ser. B 271, 383-386. 
Kalko, E., 1995. Insect pursuit, prey capture and echolocation in pipistrelle bats (microchiroptera). Animal Behaviour. 50, 861-880.

Luís, A. R., Couchinho M.N., dos Santos, M.E., 2016. A Quantitative Analysis of Pulsed Signals Emitted by Wild Bottlenose Dolphins. Ed. Bernd Sokolowski, PLoS ONE 11.7 (2016): e0157781. PMC. Web.

Laplanche, C., Adam, O., Lopatka, M and Motsch, J. -F., 2005. Male sperm whale acoustic behavior observed from multipaths at a single hydrophone. J. Acoust. Soc. Am., Vol. 118(4), 2677-2687.

Laplanche C., Adam O., Lopatka M., Motsch J.-F., 2006. Measuring the off-axis angle and the rotational movements of phonating sperm whales using a single hydrophone. J. Acoust. Soc., 119(6), 40744082.

Madsen, P. T., Wisniewska, D., and Beedholm, K., 2010. Single source sound production and dynamic beam formation in echolocating harbour porpoises (Phocoena phocoena). J. Exp. Biol., 213, 3105-3110.

Platt, M. L., \& Glimcher, P. W., 1999. Neural correlates of decision variables in parietal cortex. Nature, 400(6741), 233238.

Madsen, P. T., Johnson, M., De Soto, N. A., Zimmer, W. M., \& Tyack, P., 2005. Biosonar performance of foraging beaked whales (Mesoplodon densirostris). J. Exp. Biol, 208, 181-194.

Mann, D. A., Lu, Z., Hastings, M. C., \& Popper, A. N., 1998. Detection of ultrasonic tones and simulated dolphin echolocation clicks by a teleost fish, the American shad (Alosa sapidissima). J. Acoust. Soc. Am., 104(1), 562-568.

Mauck, B., Eysel, U., \& Dehnhardt, G., 2000. Selective heating of vibrissal follicles in seals (Phoca vitulina) and dolphins (Sotalia fluviatilis guianensis). J. Exp. Biol., 203, 2125-2131.

Miller, L.A., 2010. Prey capture by Harbor porpoises (Phocoena phocoena): a comparison between echolocators in the field and in captivity. J. Marine Acoust. Soc. Jpn., 37, 156-168.

Miller, P. J., Johnson, M. P., \& Tyack, P. L., 2004. Sperm whale behaviour indicates the use of echolocation click buzzes "creaks" in prey capture. Proc. of the Royal Society, 271, 2237-2249.

Mohl, B., Wahlberg, M., and Madsen, P., 2003. The monopulsed nature of sperm whale clicks. J. Acoust. Soc. Am., 114, 1143-1154.

Moore, P., \& Pawloski, D., 1990. Investigations of the control of echolocation pulses in the dolphin (Tursiops truncatus). In J. Thomas \& R. Kastelein (Eds), Sensory abilities of cetaceans, New York: Plenum Press, pp. 305-320.

Mullins, J., Whitehead, H., \& Weilgart, L. S., 1988. Behaviour and vocalizations of two single sperm whales, Physeter macrocephalus, off Nova Scotia. Can. J. Fish. Aquat. Sci., 45(10), 1736-1743.

Nowacek, D.P., 1999. Sound use, sequential behavior and ecology of foraging bottlenose dolphins, Tursiops truncatus (Unpublished doctoral disseration), Massachusetts Institute of Technology \& Woods Hole Oceanographic Institution, Massachusetts.

Pack, A. A., \& Herman, L. M., 1995. Sensory integration in the bottlenosed dolphin: Immediate recognition of complex shapes across the senses of echolocation and vision. J. Acoust. Soc. Am, 98(1), 722-733. 
Pack, A. A., \& Herman, L. M., 2004. Bottlenose Dolphins (Tursiops truncatus) comprehend the referent of both static and dynamic human gazing and pointing in an object-choice task. J. Comp. Psychol., 118(2), 160-171.

Pack, A. A., \& Herman, L. M., 2007. The dolphin's (Tursiops truncatus) understanding of human gazing and pointing: knowing what and where. J. Comp. Psychol., 112(1), 34-45.

Philips, J. D., Nachtigall, P. E., Au, W. W., Pawloski, J. L., \& Roitblat, H. L., 2003. Echolocation in the Risso's Dolphin, Grampus griseus. J. Acoust. Soc. Am, 113, 605-616.

Ridgway, S. H., Elsberry, W. R., Blackwood, D. J., Kamolnick, T., Todd, M., Carder, D. A., et al., 2012. Vocal reporting of echolocation targets: Dolphins often report before click trains end. J. Acoust. Soc. Am, 131(1), 593-598.

Ridgway, S. H., Moore, P. W., Carder, D. A., \& Romano, T. A., 2014. Forward shift of feeding buzz components of dolphins and belugas during associative learning reveals a likely connection to reward expectation, pleasure and brain dopamine activation. J. Exp. Biol., 217(16), 29102919.

Ridgway, S., Samuelson Dibble, D., van Alstyne, K., Price, DA., 2015. On doing two things at once: dolphin brain and nose coordinate sonar clicks, buzzes and emotional squeals with social sounds during fish capture. J. Exp. Biol., 218, 3987-3995.

Saayman, G., Wardwell Ames, E., Moffett, A., 1964. Response to novelty as an indicator of visual discrimination in the human infant. J. Exp. Child Psychol., (1)2, 189-198.
Sokal, R.R., \& Rohlf, F.J., 1973. Introduction to Biostatistics. San Francisco: Freeman and Company.

Soto, A. N., Johnson, M. P., Madsen, P. T., Díaz, F., Domínguez, I., Brito, A., \& Tyack, P., 2008. Cheetahs of the deep sea: deep foraging sprints in short finned pilot whales off Tenerife (Canary Islands). J. Anim. Ecol., 77(5), 936-947.

Thomas, J. A., Moss, C.F., Vater, M., 1992. Echolocation in Bats and Dolphins. Chicago: The University of Chicago Press.

Verfuss, U. K., Miller, L. A., Pilz, P. K., \& Schnitzler, H., 2009. Echolocation by two foraging harbour porpoises (Phocoena phocoena). J. Exp. Biol., 212, 823-834.

Whitehead, H., \& Weilgart, L., 1991. Patterns of visually observable behaviour and vocalizations in groups of female sperm whales. Behaviour, 118(3), 275-296.

Wisniewska, D.M., Johnson, M., Nachtigall, P.E., Madsen, P.T., 2014. Buzzing during biosonar-based interceptiobn of prey in the delphinids Tursiops truncatus and Pseudorca crassidens. J. Exp. Biol, 217, 4272-4282.

Zimmer, W. M. X., Johnson, M. P., D'Amico, A. \& Tyack, P. L., 2003 Combining data from a multisensor tag and passive sonar to determine the diving behavior of a sperm whale (Physeter macrocephalus). IEEE J. Ocean. Engng 28, 13-28.

Zimmer, W., Tyack, P., Johnson, M., and Madsen, P., 2005. Three-dimensional beam pattern of regular sperm whale clicks confirms benthorn hypothesis. J. Acoust. Soc. Am. 117, 1473-1485. 


\section{Funding}

This work was supported by Lyonnaise des Eaux "Partenariat environnemental et culturel » grant, ref: « Mémoire Master 2, 15 février $2012 »$ to $\mathrm{E}$. A.

\section{Acknowledgements}

We thank the whole dolphinarium team in Parc Astérix who gave so much time and contributed in many aspects, chose and designed the objects, and especially the curator Birgitta Mercera and the trainers Christel Villot and Deborah Mallet who participated in the experiment sessions.

The program script for click detection was developped by Florent Pallas, Institut de Microélectronique Electromagnétisme et Photonique - LAboratoire d'Hyperfréquences et de Caractérisation (IMEP-LAHC, Grenoble).

\section{List of abbreviations}

ICI $=$ Inter click interval

TWT $=$ Two-Way Time 